\title{
Interferon gamma (IFN- $\gamma$ ) and soluble interleukin-2 receptor (sIL-2R): combined diagnostic markers of tuberculous pleural effusion
}

\author{
Mohamed S. Abdel-Latif ${ }^{1, ~ *, ~ L o b n a ~ A . ~ A b o u-S h a m a a ~}{ }^{2}$, Eglal A. El-Sherbini ${ }^{3}$, \\ Mohamed S. M. Afifi ${ }^{2}$ \\ ${ }^{1}$ Department of Medical Laboratory Technology, Faculty of Allied Medical Science, Pharos University in Alexandria, Egypt \\ ${ }^{2}$ Department of Immunology, Medical Research Institute, University of Alexandria, Egypt \\ ${ }^{3}$ Department of Microbiology, Medical Research Institute, University of Alexandria, Egypt
}

Email address:

mohamed.abdellatif@pua.edu.eg(M. S. Abdel-Latif)

\section{To cite this article:}

Mohamed S. Abdel-Latif, Lobna A. Abou-Shamaa, Eglal A. El-Sherbini, Mohamed S. M. Afifi. Interferon Gamma (IFN- $\gamma$ ) and Soluble Interleukin-2 Receptor (sIL-2R): Combined Diagnostic Markers of Tuberculous Pleural Effusion. International Journal of Immunology. Vol. 1, No. 1, 2013, pp. 7-13. doi: 10.11648/j.iji.20130101.12

\begin{abstract}
Background: pleural TB is a diagnostic challenge because of its nonspecific clinical manifestation. The efficiency of conventional laboratory method and the reliance on pleural biopsy have motivated the evaluation of alternative diagnostic strategies. The objective of the current study is to evaluate the diagnostic efficiency of IFN- $\gamma$ and sIL2R levels in pleural effusion for differential diagnosis of tuberculous pleurisy. Methods: estimated levels of IFN- $\gamma$ and sIL2R were compared with the result of conventional PCR and Z-N staining used for detection of M. tuberculosis DNA and acid fast bacilli screening of pleural effusion, respectively. Involved study population included 60 patients with pleural effusion, divided into two groups: Tuberculous group (40 patients: 7 confirmed TB and 33 probable TB cases) and control group (20 patients: 10 cases due to malignancy and 10 cases due to heart failure). Results: our results showed that IFN- $\gamma$ and sIL-2R levels are significantly higher in tuberculous group than in control group. Conclusion: current study suggested that measurement of IFN- $\gamma$ and sIL-2R in pleural effusion could be less invasive and quicker diagnostic tools of TPE compared to conventional microbiological diagnostic methods.
\end{abstract}

Keywords: Interferon Gamma, Soluble Interleukin-2 Receptor, Tuberculosis

\section{Introduction}

Tuberculosis (TB) is one of the diseases which are most frequently associated with pleural effusion. TB pleurisy is the second most frequent form of extrapulmonary TB after TB lymphadenitis. Although various methods such as biochemical markers, cytodiagnosis, bacteriological searches and biopsy examination are used, cases with definite diagnosis are rare [1].

Tuberculous pleural effusion (TPE) is caused by a severe delayed type hypersensitivity (DTH) reaction in response to Mycobacterium TB infection. TPE usually manifests as lymphocytic exudative effusion. Tuberculous pleurisy patients generally do not present concomitant major pulmonary disease, and the majority of untreated patients reactivate within five years of pleural disease cure [2].
The pleural immune response in tuberculous pleurisy patients is characterized by the development of marked Th1 environment. Th1 response is characterized mainly by production of Interleukin-2 (IL-2) and IFN- $\gamma$, whereas Th2 responses mainly lead to production of IL-4, IL-5 and IL10. Th2 responses may be described as cross-regulatory, in that they promote antibody production and inhibit DTH [3].

A number of interesting studies have reported a preferential increase of IFN- $\gamma$ in pleural fluid and high proliferative response to tuberculous antigen of $\mathrm{T}$ lymphocytes in pleural fluid [4, 5]. Activation of Tlymphocytes leads to the expression of IL-2 receptor molecules on their cell surface and to the release of soluble IL-2 receptor molecules (sIL-2R) [6].

Tuberculous pleural effusion is a diagnostic challenge because the standard criteria for diagnosis are not invariably satisfied. And, differential diagnosis of TPE 
usually mandates invasive procedures like pleural biopsy, which is known as the gold standard [7].

The inefficiency of conventional laboratory methods and the reliance on pleural biopsy have motivated the evaluation of alternative diagnostic strategies.

Some tests that have been developed are useful in the diagnosis of tuberculous pleuritis, namely, adenosine deaminase (ADA), interferon gamma (IFN- $\gamma$ ), soluble interleukin-2 receptors (sIL-2R) and the polymerase chain reaction (PCR) for mycobacterial DNA [6,7].

Recently, a commercially available assay from Cepheid (Gene Xpert MTP/RIF, nested real time PCR) is an advance in the field of Mycobacterium tuberculosis (MTB) diagnosis. It can also identify common rifampicin (RIF) resistance. In addition to excellent sensitivity with smear positive specimens, the device is also effective in identifying $90.2 \%$ of smear negative/culture positive samples [8]. Also interferon gamma release assays (IGRAS) have been shown to be more specific for diagnosis of latent TB infection [9].

Although TB-DNA PCR, IFN- $\gamma$ and sIL-2R measurements have been evaluated individually in the diagnosis of pleural TB, obtained results for all three markers together in the same patient to improve the diagnostic efficacy of tuberculous pleural effusion are not yet available. In this study we evaluated the diagnostic efficiency of TB-DNA PCR, IFN- $\gamma$ and sIL-2R levels in pleural effusion for differential diagnosis of tuberculous pleurisy.

\section{Patients and Methods}

\subsection{Patients}

Current study was conducted on 60 patients with pleural effusion admitted to Alexandria University Hospital and/or El-Maamora Chest Hospital in Alexandria, Egypt. These patients included 40 patients with tuberculous pleural effusions ( 7 confirmed and 33 probable cases) and 20 cases with pleural effusion due to other non-infectious clinical conditions (control group; 10 cases due to heart failure and 10 cases due to malignancy).

An informed consent was obtained from all study participants or their parents or guardians.

Patient with tuberculous pleural effusion (TPE) were included in the study according to their characteristic clinical picture, suggestive X-ray findings, positive tuberculin test, lymphocytosis and increased total protein in pleural fluid.

Criteria of confirmed TB patients is to be positive Z-N stained sputum smear for acid fast bacilli (AFB), positive sputum culture on Lowenstein Jensen (LJ) media, positive for TB-DNA PCR, with total protein in pleural effusion more than $2.9 \mathrm{~g} / \mathrm{dl}$ and with lymphocytes in pleural effusion more than $80 \%$. Patients who received antituberculous treatment or corticosteroid therapy within 6 months before sample withdrawal (thoracocentesis) as well as diabetic patients were excluded from the study.

\subsection{Methods}

\subsubsection{Clinical Investigations}

This includes X-ray chest, tuberculin test, complete blood count (CBC), erythrocyte sedimentation rate (ESR), liver function test, and kidney function test. Moreover, thoracocentesis and processing of pleural effusion samples have been performed. Pleural fluid $(40 \mathrm{ml})$ was collected during the first diagnostic thoracocentesis. Each pleural fluid sample was divided into three portions. The first portion $(10 \mathrm{ml})$ was used for biochemical studies, and cytological examination; the second portion $(20 \mathrm{ml})$ was used for TB-DNA PCR; and the third portion $(10 \mathrm{ml})$ was used for measurement of IFN- $\gamma$ and sIL-2R, and to perform direct smear for ZN staining and culture on L-J media.

\subsubsection{Biochemical Investigations}

Total protein and glucose in pleural effusion was measured using commercial available kits according to manufacturer instructions (Spectrum diagnostics, Egyptian company for Biotechnology; and Spinreact, Spain, respectively).

\subsubsection{Cytological Examination}

Total leucocytic count in pleural effusion samples was calculated using improved Neubauer ruled counting chamber. Percentage of lymphocytes in pleaural effusion samples was calculated using thin film stained with Leishman's stain.

\subsubsection{Bacteriological Examination}

A smear was prepared from the pleural fluid sediment and processed for Ziehl-Neelsen (Z-N) staining of acid fast bacilli as previously described $[10,11]$. Also, portion of the pleural fluid sediment was directly inoculated onto Löwenstein-Jensen (L-J) slopes for TB culture [10, 11].

\subsubsection{Molecular Investigations}

a. DNA extraction. Pleural fluid pellet was resuspended in Tris EDTA (TE) elusion buffer and mixed with lysozyme mixture [lysozyme, Tris $\mathrm{HCl} \mathrm{pH} 8$, EDTA $(0.5$ M) and $1.2 \%$ Triton]. The mixture was incubated at $37^{\circ} \mathrm{C}$ for one hour then at $56^{\circ} \mathrm{C}$ for $30 \mathrm{~min}$ after adding proteinase K. Phenol chloroform (pH 8) was added and the mixture was incubated for $30 \mathrm{~min}$ in ice then centrifuged at $1200 \mathrm{rpm}$ for $15 \mathrm{~min} .500 \mu \mathrm{l}$ of the aqueous phase were mixed with $600 \mu \mathrm{l}$ isopropanol and incubated at $-20^{\circ} \mathrm{C}$ overnight followed by centrifugation at $1200 \mathrm{rpm}$ for 15 min. The supernatant was discarded and the pellet was washed twice in $70 \%$ ethanol and once in acetone. Each wash was followed by centrifugation at $1200 \mathrm{rpm}$ for 15 min. To elute DNA, TE buffer was added to the pellet, vortex and incubated at $56^{\circ} \mathrm{C}$ for 10 minutes [12].

b. Primers. The primers used for the amplification of a repetitive DNA sequence specific for Mycobacterium tuberculosis were 5'-CCTGCGAGCGTAGGCGTCGG-3' 
and 5'-CTCGTCCAGCGCCGCITCGG-3', which amplify a specific 123-base-pair fragment [13].

c. PCR amplification. TB-DNA in pleural effusion was detected using conventional PCR technique. Ready to go PCR beads (Amersham Pharmacia Biotech) are designed as pre mixed pre-dispensed reaction for performing PCR amplification. PCR beads are provided as dried beads that are stable at room temperature. Each bead contains all the necessary reagents, except primer and template, for performing a $25 \mu \mathrm{l}$ PCR amplification reaction. Each individual PCR reaction $(25 \mu \mathrm{l})$ contains: 1.5 unit of taq DNA polymerase, $10 \mathrm{mM}$ Tris $\mathrm{HCl}(\mathrm{pH} 9), 50 \mathrm{mM} \mathrm{MgCl} 2$, $200 \mathrm{mM}$ of each dNTP and a stabilizer. Then, extracted TB-DNA and primers were added onto each PCR reaction. The contents of each reaction tube were mixed gently and the tubes were placed in a Perkin Elmer 9600 thermocycler to perform the PCR amplification cycles. The amplified DNA products were run on $2 \%$ agarose containing ethidium bromide $(0.5 \mu \mathrm{g} / \mathrm{ml})$ by electrophoresis and visualized on UV transilluminator for positive bands.

\subsubsection{Immunological Investigations}

INF- $\gamma$ and sIL-2R levels in pleural effusion of each subject under the study were determined using quantitative sandwich-enzyme linked immunosorbent assay according to the manufacturer instructions (INF- $\gamma / \mathrm{sIL}-2 \mathrm{R}$ ELISA kit, Med system GmbH. Campus Vienna, Austria).

\subsection{Statistical Analysis of the Data}

Data obtained in the present study were statistically evaluated using SPSS version 15. Qualitative data of the two groups was analyzed using Chi-square test. Also comparison between each two groups of quantitative data was analyzed using student t-test. Receiver operating characteristic (ROC) analysis was performed to determine the diagnostic significance of INF- $\gamma$ and sIL-2R.

\section{Results}

The current study was conducted on 60 patients presented with pleural effusion. Patients under study included 40 tuberculous cases and 20 non-tuberculous control patients.

Patients with TPE included 7 cases with confirmed pleural TB (all were male patients with mean age $29.29 \pm$ 5.362 years) and 33 probable TB cases (25 males and 8 females with mean age $42.94 \pm 2.636$ years). Control patients included 10 cases with non-infectious pleural effusion due to malignancy ( 7 males and 3 females with mean age $58.80 \pm 4.386$ years) and 10 cases due to heart failure ( 8 males and 2 females with mean age $54.50 \pm$ 4.534 years).

\subsection{Bacteriological Analysis of Pleural Effusion}

Regarding Z-N staining and culture on L-J medium, pleural effusion samples in all patients under study gave negative results except confirmed TB group which tested positive.

\subsection{Biochemical and Cytological Data (Table 1)}

The mean total protein level in pleural effusion was nearly the same in malignant, confirmed and probable TB groups which were significantly higher than corresponding level in the heart failure control group.

As regards the mean glucose level, it was significantly lower in pleural effusion obtained from both confirmed and probable TB groups of patients than in the heart failure and malignant groups. Moreover, it was significantly lower in the confirmed TB group than in the probable TB group.

Mean total leucocytic count of pleural fluid in confirmed and probable TB groups was significantly lower than in malignant group but significantly higher than in heart failure group.

The mean percentage of lymphocytes in pleural effusion was significantly higher in both confirmed TB and probable TB groups than in the malignant control group. On the other hand, lymphocyte percentage was only significantly higher in the confirmed TB group than in the heart failure control group. In addition, mean lymphocyte percentage was significantly higher in the confirmed TB group than in the probable TB group.

Table 1. Biochemical and cytological characteristics of pleural effusion in control and tuberculous groups of patients

\begin{tabular}{|c|c|c|c|c|c|}
\hline \multirow[b]{2}{*}{ Parameter } & & \multicolumn{2}{|c|}{ Control patients (20) } & \multicolumn{2}{|c|}{ Tuberculous patients (40) } \\
\hline & & $\begin{array}{l}\text { Malignant } \\
(\text { No. = 10) }\end{array}$ & $\begin{array}{l}\text { Heart failure } \\
(\text { No. }=10)\end{array}$ & $\begin{array}{l}\text { Confirmed TB } \\
(\text { No. }=7)\end{array}$ & $\begin{array}{l}\text { Probable TB } \\
(\text { No. }=33)\end{array}$ \\
\hline \multirow{6}{*}{$\begin{array}{l}\text { Total protein } \\
\text { (g/dl) }\end{array}$} & Range & $3.6-4.9$ & $1.9-3.1$ & $3.6-5.0$ & $3.0-5.7$ \\
\hline & Mean & 4.39 & 2.30 & 4.39 & 4.33 \\
\hline & SE & 0.15 & 0.16 & 0.19 & 0.12 \\
\hline & P1 & & $<0.001 *$ & 0.986 & 0.812 \\
\hline & P2 & & & $<0.001 *$ & $<0.001 *$ \\
\hline & P3 & & & & 0.852 \\
\hline \multirow{6}{*}{$\begin{array}{l}\text { Glucose } \\
(\mathrm{mg} / \mathrm{dl})\end{array}$} & Range & $73.3-96.8$ & $80.0-123.0$ & $33.3-55.2$ & $25.0-153.7$ \\
\hline & Mean & 85.91 & 103.36 & 47.93 & 65.16 \\
\hline & SE & 2.31 & 4.57 & 2.69 & 4.82 \\
\hline & P1 & & $<0.001^{*}$ & $<0.001 *$ & $<0.001^{*}$ \\
\hline & P2 & & & $<0.001 *$ & $<0.001^{*}$ \\
\hline & P3 & & & & $0.004 *$ \\
\hline
\end{tabular}




\begin{tabular}{llllll}
\hline & Range & $4800-9850$ & $960-3350$ & $2000-4600$ & $1000-12600$ \\
& Mean & 6630.00 & 2066.00 & 320.00 & 4183.55 \\
Total leucocytic count & SE & 612.88 & 270.04 & 371.61 & 440.10 \\
(cells/mm $\left.\mathbf{m m}^{3}\right)$ & P1 & & $<0.001^{*}$ & $<0.001^{*}$ & $0.008^{*}$ \\
& P2 & & & $0.023^{*}$ & $<0.001^{*}$ \\
& P3 & & & 0.321 \\
& Range & $2-42$ & $15-100$ & $80-100$ & $0-100$ \\
Lymphocytes & Mean & 21.00 & 67.80 & 91.57 & 55.18 \\
(\%) & SE & 5.07 & 9.43 & 2.68 & 5.42 \\
& P1 & & $<0.001^{*}$ & $<0.001^{*}$ & $<0.001^{*}$ \\
& P2 & & & $0.035^{*}$ & 0.265 \\
\hline
\end{tabular}

P1: Significant level when malignant group was compared with other groups.

P2: Significant level when heart failure group was compared with other groups.

P3: Significant level when confirmed TB group was compared with probable TB group.

*: Significant difference at $\mathrm{p} \leq 0.05$.

\subsection{Immunological Data}

The sensitivity of ELISA kit for detection of IFN- $\gamma$ and sIL-2R was $1.5 \mathrm{pg} / \mathrm{ml}$ and $0.04 \mathrm{ng} / \mathrm{ml}$, respectively. Themean levels of IFN- $\gamma$ in the pleural effusion of the malignant and heart failure control groups were 1.54 and $1.78 \mathrm{pg} / \mathrm{ml}$, respectively. The mean levels of sIL-2R in the pleural effusion of the malignant and heart failure control groups were 19.61 and $12.51 \mathrm{ng} / \mathrm{ml}$, respectively. Hence, the cut off levels of IFN- $\gamma$ and sIL-2R calculated according to these values were $3 \mathrm{pg} / \mathrm{ml}$ and $20 \mathrm{ng} / \mathrm{ml}$, respectively.

\section{A. IFN- $\gamma$}

The level of IFN- $\gamma$ in malignant group ranged from 1.19 to $2.25 \mathrm{pg} / \mathrm{ml}$ while in heart failure group it ranged from 1.3 to $2.4 \mathrm{pg} / \mathrm{ml}$ with nearly the same mean values $(1.54 \pm$ $0.1 \& 1.78 \pm 0.11 \mathrm{pg} / \mathrm{ml}$, respectively). None of the patients belonging to these groups had IFN- $\gamma$ level $>3$ $\mathrm{pg} / \mathrm{ml}$.

On the other hand, the level of IFN- $\gamma$ in pleural effusion of confirmed TB group of patients ranged from 15.95 to $125.08 \mathrm{pg} / \mathrm{ml}$ while in probable TB group it ranged from 1.47 to $163.41 \mathrm{pg} / \mathrm{ml}$ with mean levels of $61.56 \pm 13.58$ and $38.45 \pm 8.49 \mathrm{pg} / \mathrm{ml}$, respectively. All patients included in the confirmed TB group $(7 / 7,100 \%)$ had IFN- $\gamma$ level $>3$ $\mathrm{pg} / \mathrm{ml}$ while in the probable TB group only $45.45 \%$ of them $(15 / 33)$ had IFN- $\gamma$ level $>3 \mathrm{pg} / \mathrm{ml}$.

The mean levels of IFN- $\gamma$ in confirmed and probable TB groups were significantly higher than those in pleural effusion due to malignancy $(\mathrm{P}<0.001$ and $\mathrm{P}=0.008$, respectively) and heart failure $(\mathrm{P}<0.001$ and $\mathrm{P}=0.008)$, respectively. Moreover, pleural effusion from patients with confirmed TB showed significantly higher level of IFN- $\gamma$ than corresponding value in patients with probable $\mathrm{TB}, \mathrm{P}=$ 0.011 (Figure 1).

\section{B. $s I L-2 R$}

All patients included in confirmed TB group $(7 / 7,100 \%)$ had sIL-2R $>20 \mathrm{ng} / \mathrm{ml}$ while in probable TB group only $51.51 \%$ of them $(17 / 33)$ had sIL-2R level $>20 \mathrm{ng} / \mathrm{ml}$. On the other hand, $50 \%$ of malignant group $(5 / 10)$ and none of heart failure group had sIL-2R level $>20 \mathrm{ng} / \mathrm{ml}$.
sIL-2R in pleural effusion of confirmed TB group ranged from 22.0 to $29.9 \mathrm{ng} / \mathrm{ml}$ with a mean level of 27.08 $\pm 1.00 \mathrm{ng} / \mathrm{ml}$ which was significantly higher than corresponding level in malignant (mean level $19.61 \pm 1.86$ $\mathrm{ng} / \mathrm{ml}$ ), $\mathrm{P}=0.044$ and heart failure control groups (mean level $12.51 \pm 1.65 \mathrm{ng} / \mathrm{ml}), \mathrm{P}<0.001$.

SIL-2R in pleural effusion of probable TB group ranged from 4.7 to $28.4 \mathrm{ng} / \mathrm{ml}$ with a mean level of $19.37 \pm 1.38$ $\mathrm{ng} / \mathrm{ml}$ which was significantly higher than corresponding level in heart failure control group, $\mathrm{P}=0.003$. Moreover, the level of sIL-2R in pleural effusion of confirmed TB group was significantly higher than corresponding level in probable TB group of patients, $\mathrm{P}=0.03$ (Figure 2).

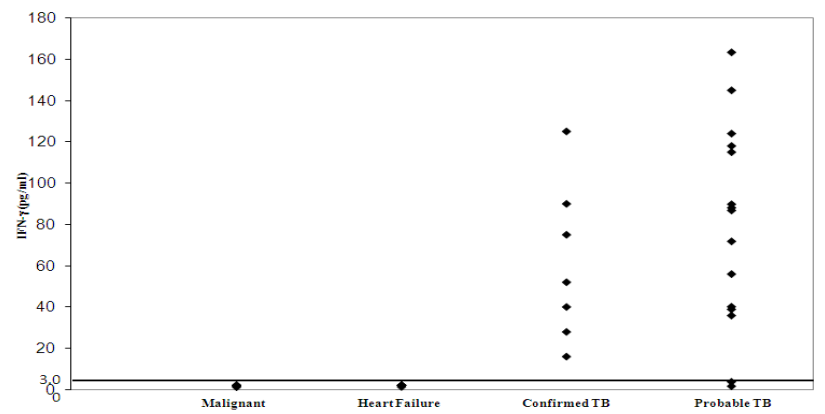

Figure 1. Distribution of pleural effusion IFN- $\gamma$ levels ( $\mathrm{pg} / \mathrm{ml}$ ) among control and tuberculous groups of patients (NB. Cut off value $=3 \mathrm{pg} / \mathrm{ml}$ ).

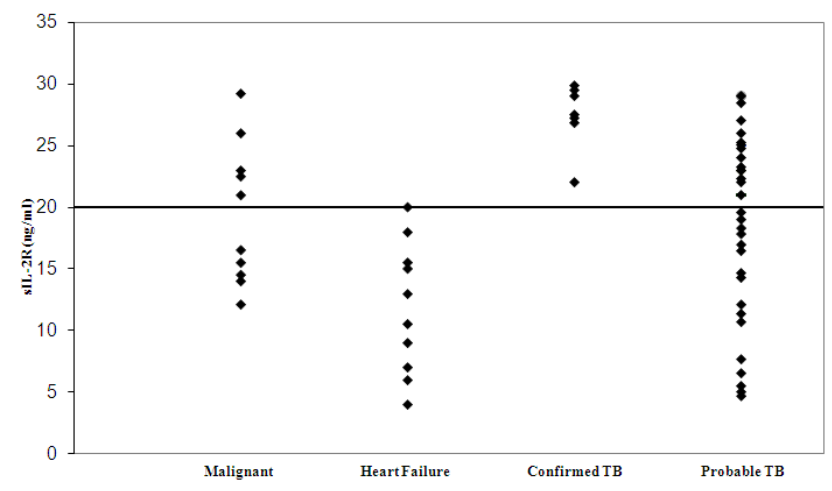

Figure 2. Distribution of pleural effusion sIL-2R levels ( $\mathrm{ng} / \mathrm{ml}$ ) among control and tuberculous groups of patients (NB. Cut off value $=20 \mathrm{ng} / \mathrm{ml}$ ) 


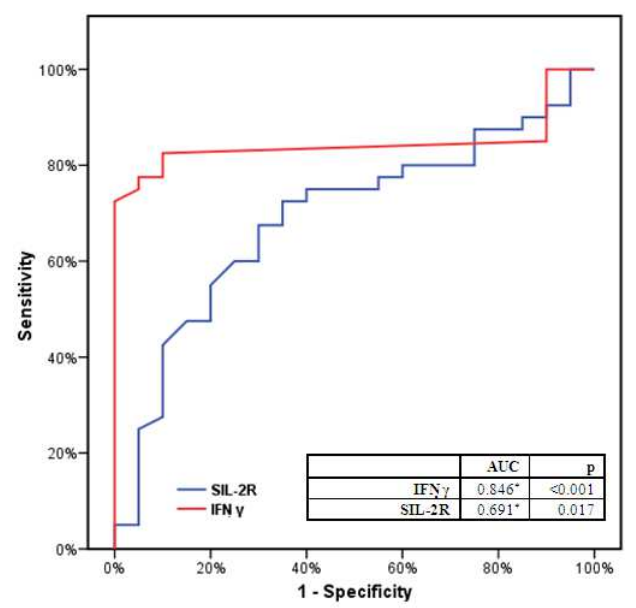

Figure 3. ROC analysis for diagnostic significance of $I F N-\gamma$ and $S I L-2 R$.

As shown in Figure 3, ROC analysis demonstrated that IFN- $\gamma$ is the most sensitive and specific indicator of

tuberculous pleuritis than sIL-2R (area under the curve [AUC], 0.846 and 0.691 , respectively). The sensitivity and specificity of IFN- $\gamma$ are $82.5 \%$ and $90 \%$, respectively; whereas, the sensitivity and specificity of sIL-2R are $72.5 \%$ and $65 \%$, respectively.

\subsection{Molecular Data}

Regarding the control groups, none of the malignant patients but only two out of 10 patients with heart failure $(20 \%)$ were positive for TB-DNA by PCR. On the other hand, all patients of the confirmed TB group $(7 / 7,100 \%)$ and only 18 out of the 33 patients $(54.5 \%)$ of the probable TB group were positive for TB-DNA PCR (data not shown)

The percentage of positive cases for TB-DNA was significantly higher in both tuberculous groups than in control groups, $\mathrm{P}<0.001$.

\subsection{Relation between Cytological, Immunological and \\ Molecular Data (Table 2)}

Table 2. Number of patients having positive cytological, immunological and molecular data in pleural effusion

\begin{tabular}{|c|c|c|c|c|c|c|}
\hline Groups & & $\begin{array}{c}\text { AFB positive } \\
\text { (No. } / \%)\end{array}$ & $\begin{array}{c}\text { IFN- } \gamma \\
\text { positive } \\
>3 \mathrm{pg} / \mathrm{ml} \\
(\mathrm{No} / \% \text { ) } \\
\end{array}$ & $\begin{array}{c}\text { sIL-2R positive } \\
>20 \mathrm{ng} / \mathrm{ml} \\
(\mathrm{No} / \%)\end{array}$ & $\begin{array}{c}\text { TB-DNA PCR } \\
\text { (No. } / \%)\end{array}$ & $\begin{array}{c}\text { Lymphocytes } \\
\text { positive } \\
>80 \% \\
\text { (No. } / \%)\end{array}$ \\
\hline \multirow{2}{*}{$\begin{array}{l}\text { Non-tuberculous pleural } \\
\text { effusion (Control groups) } \\
\text { (No. }=20)\end{array}$} & $\begin{array}{l}\text { Malignant } \\
(\text { No. }=10)\end{array}$ & $0 / 0$ & $0 / 0$ & $5 / 50$ & $0 / 0$ & $0 / 0$ \\
\hline & $\begin{array}{l}\text { Heart failure } \\
(\text { No. }=10)\end{array}$ & $0 / 0$ & $0 / 0$ & $0 / 0$ & $2 / 20$ & $3 / 30$ \\
\hline \multirow{3}{*}{$\begin{array}{l}\text { Tuberculous pleural effusion } \\
\qquad(\text { No. }=40)\end{array}$} & $\begin{array}{l}\text { Confirmed TB } \\
(\text { No. }=7)\end{array}$ & $7 / 100$ & $7 / 100$ & $7 / 100$ & $7 / 100$ & $7 / 100$ \\
\hline & $\begin{array}{c}\text { Probable TB } \\
(\text { No. }=33)\end{array}$ & $0 / 0$ & $15 / 45.45$ & $17 / 51.51$ & $18 / 54.5$ & $17 / 51.51$ \\
\hline & Total results of TBE & $7 / 17.5$ & $22 / 55$ & $24 / 60$ & $25 / 62.5$ & $24 / 60$ \\
\hline
\end{tabular}

$\mathrm{AFB}=$ Acid Fast Bacilli

Pleural effusion samples from all patients under study were negative for AFB using Z-N stain, except confirmed TB group which tested positive.

All patients with confirmed TB had IFN- $\gamma$ and sIL-2R levels more than corresponding cut off points, positive TBDNA PCR results, and lymphocyte percentages more than $80 \%$. When probable TB group was concerned, $45.45 \%$ of patients had IFN- $\gamma$ more than cut off point, $51.51 \%$ had SIL-2R more than cut off point, $54.5 \%$ had positive TBDNA PCR results, and 51.51\% had lymphocyte percentages more than $80 \%$.

The specificities of IFN- $\gamma$, sIL-2R, and TB-DNA PCR were $100 \%, 75.0 \%$ and $70.0 \%$, respectively.

\section{Discussion}

In the current study we evaluated the relevance of IFN- $\gamma$ and sIL-2R levels as compared to TB-DNA PCR and conventional microbiological methods for diagnosis of TPE. Also biochemical and cytological investigations of pleural effusion were performed to evaluate their significance in preliminary diagnosis of TPE.
The first step in the evaluation of pleural effusion is to determine whether an effusion is transudative or exudative. In the current study such differentiation depended on estimation of absolute total protein in pleural effusion ( $>$ $2.9 \mathrm{~g} / \mathrm{dl}$ ) [14]. Our data showed that the mean absolute total protein in pleural effusion of patients with TB as well as those with malignancy was nearly $4 \mathrm{~g} / \mathrm{dl}$, while in patients with heart failure the corresponding level was approximately $2 \mathrm{~g} / \mathrm{dl}$. The glucose level in pleural effusion changes according to the clinical conditions. Leers et al., reported its decrease $(<60 \mathrm{mg} / \mathrm{dl})$ in $\mathrm{TB}$ and its increase ( $>$ $60 \mathrm{mg} / \mathrm{dl}$ ) in malignant cases [14]. Our results were in agreement with these findings as regards confirmed TB and malignant groups.

Similarly, in transudative pleural effusion (heart failure group) the mean glucose level was significantly higher than in both confirmed and probable TB groups of patients.

In this study the pleural effusion total leucocytic count was significantly lower in the heart failure group than in all other studied groups of patients. These results were in consistency with previous reports [15-17]. The percentage of lymphocytes in pleural effusion was significantly higher 
in patients with confirmed TB than all patients in other studied groups. Although applied biochemical and cytological data can be used for preliminary differentiation between exudative and transudative pleural effusion, such parameters cannot be considered as conclusive markers that aid in the diagnosis of TPE.

IFN- $\gamma$ is an immune regulator that increases the phagocytic activity for mycobacteria and plays a key role in immune response in TB pleurisy [18].

Our results revealed that IFN- $\gamma$ was significantly higher in tuberculous groups as compared to control groups. Moreover, it was significantly higher in confirmed TB than in probable TB group. Observed data were in agreement with previous reports that looked for the utility of IFN- $\gamma$ levels in differential diagnosis of TPE [5, 6, 19-21].

In case of sIL-2R level, it was significantly higher in pleural effusion of confirmed than in malignant control group. This difference was not observed between probable TB and malignant control group. Moreover, the mean level of sIL-2R in pleural effusion of confirmed and probable TB groups was significantly higher than corresponding level in heart failure control group. These results are in agreement with previous studies that measured sIL-2R levels in pleural effusion $[15,16]$. Current results also supported previous reports looking for simultaneous assessment of IFN- $\gamma$ and sIL-2R in patients with TPE [6, $20,21]$.

Theoretically; PCR for the M. tuberculosis genome should be highly effective and rapid in diagnosing tuberculous pleuritis. However, the solitary application of TB-DNA PCR for the diagnosis of TPE has important limitations; among them are false negative and false positive results [22].

Our results regarding the studied tuberculous groups showed that all patients with confirmed TB and 18 out of the 33 patients $(54.5 \%)$ with probable TB were positive for TB-DNA PCR. In the control group, none of malignant patients and only 2 out of the 10 patients with heart failure were positive for TB-DNA PCR.

According to our result, the PCR showed a specificity of $70 \%$. This performance is supposed to be much better by using real-time PCR/Xpert MTB/RIF assay, where the specificity to detect TB is $90-100 \%$ with sensitivity more than $95 \%$ [23].

Obtained data suggest that, negative results of IFN- $\gamma$ but not those of sIL-2R or TB-DNA PCR could provide assured exclusive diagnostic marker for negative cases. Consequently, the results of sIL-2R and TB-DNA PCR need to be confirmed by those of IFN- $\gamma$.

In conclusion, current study suggested that measurement of IFN- $\gamma$ and sIL-2R in pleural effusion could be less invasive and quicker diagnostic tools of TPE compared to conventional microbiological diagnostic methods. In addition, clinical data together with measurement of IFN- $\gamma$, sIL-2R and detection of TB-DNA by PCR as well as lymphocytosis in pleural effusion could provide the basis for rapid and efficient diagnosis of TPE in different clinical settings. Such coexistence was clearly observed in $100 \%$ of confirmed TB group as well as about $50 \%$ of probable TB group.

\section{Acknowledgements}

The authors thank all staff members of the Chest department, Alexandria Hospital and El Maamoura Chest Hospital for their help and support. Authors also appreciate the grate cooperation and help offered by Prof. Dr. AbdelMonem K. Rabie, Chest department, Faculty of Medicine, University of Alexandria, Egypt.

Ethical approval: This study was approved by the local ethics committee of the Medical Research Institute, University of Alexandria.

Conflict of interest: No conflict of interest to declare.

\section{References}

[1] A. Trajman, M. Pai, K. Dheda, et al. "Novel tests for diagnosing tuberculous pleural effusion: what works and what does not?" Eur Respir J, 31:1098-06, 2008.

[2] J. Ellner, P. Barnes, R. Wallis, R. Modlin. "The Immunology of tuberculous pleurisy." Semin Respir Infect, 3:335-42, 1988 .

[3] S. Sharma, D. Mitra, A. Balamurugan, R. Pandey, N. Mehra. "Cytokine polarization in 12 ilitary and pleural tuberculosis." J Clin Immunol, 22:345-52, 2002.

[4] W. Somkiat, S. Udomsak, R. Kiat, U. Visit, L. Sakchai, C. Pradit, N. Chaivej. "Interferon gamma for diagnosing tuberculous pleural effusions." Thorax, 54:921-4, 1999.

[5] K. Aoe, A. Hiraki, T. Murakami, R. Eda, T. Maeda, K. Sugi, H. Takeyama. "Diagnostic significance of interferon gamma in tuberculous pleural effusion." Chest, 123:740-4, 2003.

[6] Y. K. Kim, S. Y. Lee, S. S Kwon, K. H. Kim, H. S. Moon, J. S. Song, S. H. Park. "Gamma-interferon and soluble interleukin 2 receptor in tuberculous pleural effusion." Lung, 176:175-84, 2001.

[7] R. W. Light. "Establishing the diagnosis of tuberculous pleuritis." Arch Intern Med, 158:1967-8, 1998.

[8] C. C. Boehme, M. P. Nicol, P. Nabeta, J. S. Michael, E. Gotuzzo, R. Tahirli et al. "Feasibility, diagnostic accuracy, and effectiveness of 12 ecentralized use of the Xpert MTB/RIF test for diagnosis of tuberculosis and multidrug resistance: a multicentre implementation study." Lancet, 377(9776):1495-05, 2011.

[9] L. M. Pinto, J. Grenier, S. G. Schumacher, C. M. Denkinger, K. R. Steingart, M. Pai. "Immunodiagnosis of tuberculosis: state of the art." Med Princ Pract, 21(1):4-13, 2012.

[10] D. Yang, Y. Kim, J. Lee, S. Kim, W. Lee. "A prospective study of Ziehl-Neelsen stain and Mycobacterial culture of pleural fluid and closed pleural biopsy specimen in tuberculous pleural effusion." Korean J Infect Dis, 32:55-9, 2000.

[11] S. Chakravorty, M. Sen, J. Tyagi. "Diagnosis of extrapulmonary tuberculosis by smear, culture, and PCR 
using universal sample processing technology." Clin Microbiol, 43:4357-62, 2005.

[12] J. Sambrook, E. Fritsch, T. Maniatis. "DNA extraction and purification in molecular cloning: a laboratory manual." $2^{\text {nd }}$ edition. Cold Spring Harbor Laboratory Press USA, p. 21$110,1989$.

[13] K. Eisenach, M. Cave, J. Bates, J. Crawford. "Polymerase chain reaction amplification of a repetitive DNA sequence specific for Mycobacterium tuberculosis." J Infect Dis, 161:977-981, 1990.

[14] M. Leers, H. Kleinveld, V. Scharnhorst. "Differentiating transudative from exudative pleural effusion: should we measure effusion cholesterol dehydrogenase?" Clin Chem Lab Med, 45:1332-8, 2007.

[15] J. Porcel, I. Gázquez, M. Vives, B. Pérez, M. Rubio, M. Rivas. "Diagnosis of tuberculous pleuritis by the measurement of soluble interleukin 2 receptor in pleural fluid." Int J Tuberc Lung Dis, 4:975-9, 2000.

[16] S. Harita, N. Nogami, T. Kikuchi, M. Kibata. "Preliminary evaluation of soluble IL-2 receptor and type III procollagen $\mathrm{N}$-terminal aminopeptide in pleural fluid for differentiating tuberculous, carcinomatous and parapneumonic pleural effusions." Respirology, 7:311-5, 2002.

[17] C. Alemán, L. Sanchez, J. Alegre, et al. "Differentiating between malignant and idiopathic pleural effusion: the value of diagnostic procedures." Quart J Med, 100:351-9, 2007.

[18] L. Valdes, A. Pose, E. S. Jose et al. "Tuberculous pleural effusion." Eur Int Med, 14:77-88, 2003.

[19] J. Jiang, H. Shi, Q. Liang, S. Qin, X. Qin. "Diagnostic value of interferon-gamma in tuberculous pleurisy: a metaanalysis." Chest, 131:1133-44, 2007.

[20] T. Tsao, C. Huang, W. Chiou, P. Yang, M. Hsieh, K. Tsao. "Levels of interferon-gamma and interleukin-2 receptoralpha for bronchoalveolar lavage fluid and serum were correlated with clinical grade and treatment of pulmonary tuberculosis." Int J Tuberc Lung Dis, 6:720-7, 2002.

[21] A. Hiraki, K. Aoe, R. Eda, T. Maeda, T. Murakami, K. Sugi, H. Takeyama. "Comparison of six biological markers for the diagnosis of tuberculous pleuritis." Chest, 125:987-9, 2004.

[22] A. Bahador, H. Etemadi, B. Kazemi, R. Ghorbanzadeh, F. Nakhjavan, Z. Nejad. "Performance assessment of IS1081PCR for direct detection of tuberculous pleural effusion: compared to rpoB-PCR." Res J Agric Biol Sci, 1:142-5, 2005.

[23] D. I. Ling, L. L. Flores, L. W. Riley, M Pai. "Commercial nucleic-acid amplification tests for diagnosis of pulmonary tuberculosis in respiratory specimens: meta-analysis and meta-regression." PLoS One, 3(2):e1536, 2008. 